\title{
Hiding and being hidden: The marginalisation of children's participation in research and practice responses to domestic violence and abuse
}

\author{
Ruth Elliffe ${ }^{1}$, Stephanie Holt ${ }^{1}$, Carolina $\varnothing$ verlien $^{2}$
}

\begin{abstract}
When it comes to researching children and adolescents' experiences of domestic violence, this group is known within the literature to be a hard to reach population. This is namely due to their perceived vulnerability, as well as efforts to protect them by adult gatekeepers, and rigorous ethical procedures that make recruitment efforts often challenging. Consequently, this group, sometimes for their own protection, remain hidden in the shadows when it comes to research and practice responses that continue to operate from an adultcentric lens when children's agency is not fully acknowledged. This paper sets out to discuss the multiple ways by which children who experience domestic violence both hide and are hidden by adults, rendering them invisible. Based on findings from a qualitative doctoral study that sought to explore children's experiences of the police response to domestic violence, this paper highlights the interconnectedness between children's invisibility in practice and research, and the processes through which they become and can remain hidden in these two arenas. The paper calls for a need to bring children's experiences of domestic violence out of the shadows and to begin to acknowledge their agency and capacity as both research participants and victims.
\end{abstract}

1. School of Social Work and Social Policy, Trinity College Dublin, Ireland

2. Associate professor, School of Social Work and Social Policy, Trinity College, Dublin,Ireland 3. Norwegian Center for Violence and Traumatic Stress Studies (NKVTS), Norway, and Stockholm University, Sweden.

Address for correspondence: relliffe@tcd.ie

Date of first (online) publication: 


\section{Introduction}

A growing number of qualitative studies concerned with capturing the child's experience of domestic violence have been instrumental in illuminating the nature of children's involvement in abusive homes and the strategies they use to protect themselves and family members from acts of violence and patterns of control (Callaghan and Alexander, 2015; Katz, 2016; Øverlien, 2017). Historically, children's experiences of abuse were reported by adult informants in research and these reports have been criticised for failing to capture the subjective experience of the child, often minimising their involvement and position as 'victim', separate to that of the adult's experience (Edleson, 1999). Children, once considered to be 'passive bystanders', whose needs were best met through supporting the adult victim, are now recognised as agentic beings that require more attention in practice responses (Callaghan and Alexander, 2015). Within the domestic violence literature, there is a growing concern with ascertaining the child's views on matters including post-separation contact with an abusive parent (Holt, 2011; 2015); therapeutic interventions (Pernebo and Almqvist, 2016); policy development (Houghton, 2018); as well as the response of professionals including the police (Richardson-Foster et al., 2012; Stanley, Miller and Foster, 2012; Øverlien and Aas, 2016), in order to develop more child-centred responses. Although much has been done in repositioning the child's needs in policy, practice and research, there are still challenges when it comes to including children's voices in domestic violence research, which we shall argue are closely connected to children's invisibility in practice. These challenges can result in children becoming a 'hard to reach population' and one that remains on the periphery of scientific inquiry. When it comes to accessing a hidden population, Hill offers that 'research can provide an opportunity for otherwise silenced voices to be heard, if not necessarily listened to' (2015, p. 344). Much weight has been given to including children's voices in research, yet it is only recently that researchers in the field of domestic violence have shed light on children as agents (Callaghan and Alexander, 2015; Katz, 2016; Øverlien, 2017). One might argue that a lack of understanding regarding children's agency is partly the reason for them being hidden in practice settings. However, it is for this very reason that researchers cannot gain access to children since they are hidden victims in practice.

Drawing selectively from doctoral research conducted by the first author in Ireland that sought to explore children and young people's experiences of the police response to domestic violence (Elliffe, 2019), this paper will show how children both hide and are hidden in research and practice and the interconnectedness of both. The paper will begin with a discussion on children's invisibility in research, looking at the challenges in recruiting this group and specifically the layers of gatekeeping that can prevent children being seen in this context. This will be followed by an investigation in to how children are hidden in practice, by looking at mothers' efforts to protect children by hiding the abuse from them and children themselves who hide as a way 
to protect themselves and siblings, making it more difficult for both practitioners and researchers to access them as their position of victim remains in the shadows.

\section{Accessing children's voices in domestic violence research: The gatekeeping layer}

Understandings of childhood and children's agency arising from the 'new sociology of childhood' (Tisdall and Punch, 2012; James and Prout, 1997), and the positioning of children as active citizens with a prescribed set of rights enshrined in the United Nations Convention on the Rights of the Child (United Nations, 1989), provide the backdrop to a wide debate on the methodological and ethical issues surrounding children's inclusion in research (Graham, Powell and Taylor, 2015; James, 2007). Central to the debate on children's participation in research is their status of 'child' (Powell and Smith, 2009). It is argued that developmentally, the child, because of their age and physical stature, represents a vulnerability that requires the protection of adults to act in a gatekeeping role, particularly when it comes to their inclusion in research of a sensitive nature (Øverlien and Holt, 2018; Graham et al., 2015; Morris, Kelsey and Humphreys, 2012; Powell and Smith, 2009). Researchers must, therefore, negotiate access to children through a hierarchy of gatekeepers that begins with a rigorous process of ethical approval, and can lead to difficulties as Campbell (2008) discovered in his attempts to recruit children to a study on parental separation. Campbell (2008) found a disconnect between the university research ethics committee (REC) and the research topic, which resulted in considerable caution being taken when it came to legalities and assessment of risk, when compared with the approval process from external family service agencies. Such caution Campbell argues was 'based on different understandings of the separation process and its effects on children' (2008, p. 35).

Whilst the use of agency gatekeepers is a common approach taken by children's researchers, there is a risk of practitioners assuming a protective stance, focusing on the potential risk of re-traumatisation in their decision about who is suitable or not suitable to participate (Powell and Smith, 2009). Such a risk-averse approach can often result in a small pool, if one at all, of potential child participants to recruit from ( $\varnothing$ verlien and Holt, 2018; Campbell, 2008). The potential risk of re-traumatisation must be weighed against any benefit (McClinton Appollis et. al., 2015), however, this is more often difficult to fully assess as children are not a homogenous group and may respond in different ways to participating in sensitive research (Cater and $\varnothing$ verlien, 2014; Morris et. al., 2012). In a similar discussion, Øverlien \& Holt (2018), found there to be little support in the scientific literature for the theory of re-traumatization of children during research interviews, yet it is often seen as a barrier to including children in domestic violence research. Indeed, Campbell argues that 'when children are denied knowledge about research that directly affects them because of adult 
concerns about possible 'damage' to them, their ability to decide for themselves is also denied' (2008, p. 42). Children's marginalisation thus has a paternalistic effect (Hill and Tisdall, 1997). This perceived understanding of children as vulnerable and at risk may in fact lead to what Downes, Kelly and Westmarland (2014) cite as 'a dangerous lack of evidence', whereby practice responses fail to identify the child as victim largely because of a lack of evidence to support their needs. Baker (2005) argues that it is the lack of domestic violence research involving children that has led to a scarcity in the provision of services to them.

There has been a tendency in the literature, as Katz (2015) describes, to focus on 'the deficits and pathologies' (p. 153) of those who have experienced domestic violence, and she argues for a shift in thinking. Powell and Smith (2009) suggest that 'gatekeepers who work professionally with children who are considered especially vulnerable, should become more aware of children's competencies and their rights to participation' (p. 139). Indeed, recent contributions to the literature demonstrate children's capacity as research participants and their ability to manage how they disclose experiences of domestic violence in a research setting (Callaghan et al., 2017), using strategies to avoid researchers' questions (Evang and Øverlien, 2015). However, beyond targeting specialist services that support children experiencing domestic violence, it can be difficult to reach this population since reports show that only small numbers of women and their children will seek formal supports through those services (Nixon et al., 2017). Similarly, the under-reporting of the issue suggests that many families experiencing violence and abuse, may never come into contact with specialist domestic violence services (McIntosh, 2003), making it difficult to reach children and young people within a broader community sample.

Informed consent must be secured from a parent, or in some legal contexts both parents, before contact can be made with the child, adding an additional layer to the gatekeeping process (Carroll-Lind et al, 2006; Cashmore, 2006; Cater and $\emptyset$ verlien, 2014). Parental consent can become problematic when research involves children speaking about a sensitive family issue (Hill, 2015, Cater and Øverlien, 2014), or children's own participation in risk behaviours which they may not wish to disclose to a parent, but might however be happy to talk about in a research capacity (Liu et al., 2017). In this way a guardian may act as a barrier to children's participation by not consenting even when the child may wish to do so (Wyness, 2006). Consequently, adult gatekeepers have the power to hold the door closed to children's participation in research at multiple stages in the research process, and may do so based on a perception of children as vulnerable and in need of protection (Powell and Smith, 2009). However, that door can be closed more firmly by gatekeepers when the research topic is considered sensitive and seeks to explore children's lived experience of that sensitive subject.

Lastly, children themselves may not agree to participate, in particular adolescents for whom Hill (2006) suggests participation in research may not be a high priority, and who may in fact consider the invitation as an 'unwelcome intrusion' into their 
private life (p. 77), thereby making them harder to reach. On the other hand, young people may welcome the opportunity to have their voice heard but do not always have the time to commit to participation amidst busy social and personal lives.

\section{Some considerations in seeking parental consent}

The requirement of parental consent can render children voiceless in research, particularly when it is on a sensitive topic (Liu et al., 2017; Coyne, 2010). There is a general agreement within the literature on the need for parental consent for children, however some contention remains whether adolescents should be allowed to consent to research without parental permission. The need for parental consent beyond the age of 16 to participate in research varies across jurisdictions, suggesting a cultural aspect to it (Cater and Øverlien, 2014). Indeed, practices on, if, and how to include children and adolescents in research vary considerably between and sometimes within countries (Øverlien and Holt, 2018). In a discussion on extending the right to consent to mature minors (over 16 years of age) in healthcare research in the US, Iltis (2013) draws attention to some of the key arguments in this debate that are also relevant here. Firstly, limiting children's involvement in research indirectly through restrictive consent procedures and risk-based decision making, may deny children 'the benefits of knowledge gained through research' (p. 336). Additionally, the need for parental consent can lead to lower response rates and skewed samples, and lastly 'may mean that adolescents are unjustly excluded from studies' (p. 339). Nevertheless, Iltis (2013), from a healthcare research perspective, argues that mature minors do not have the 'cognitive and emotional capacities required to give informed consent' (p. 340) and as a 'child', parental authority over them should be recognised up until the age of 18. In contrast, the new paradigm of childhood studies challenges this by suggesting that researchers can help to build a young person's capacity to consent by developing child-centred methodologies (James and Prout, 1997), and viewing consent seeking as an on-going process, through which the child has ample opportunity to opt in or out (Alderson and Morrow, 2011; Cashmore, 2006). Within this framework children are constructed as active social agents who should be enabled to have a voice in research which should be listened to beyond the academic and into daily life (James, 2007). Still, parents remain 'the dominant reference points when negotiating access, reflecting their structurally superior position within the hierarchy' (Wyness, 2012, p. 215), which remains more in line with Ilits' (2013) argument on the requirement for parental consent up to the age of 18 years.

Within the domestic violence arena, the process of seeking parental consent is further complicated when researchers must involve an abusive parent in the process. Seeking or not seeking consent from an abusive parent for their child's inclusion in research that will invariably involve them talking about their experiences of the abuse is precarious, for a number of reasons (Cater and Øverlien, 2014). This is not an issue that is dealt with at any great length in the literature, but has been 
highlighted by researchers in the field as an area of concern that ethical boards should be more privy to (Cater $\& \varnothing$ verlien, 2014; Morris et al., 2012). Morris et al. (2012) drawing on international literature, argue that 'in domestic violence research, it is often appropriate to seek the consent of the non-offending parent only' (p. 128), once it is deemed safe to do so and the child has available supports. However, Cater $\& \varnothing$ verlien (2014) suggest that children may still be put at risk if the perpetrator discovers they took part without their consent, yet at the same time may also be placed at risk by researchers' attempts to seek the perpetrator's consent. In Ireland, there is a legal requirement for both parents to be informed of and provide consent to their child's participation in research, having serious implications for children's participation, particularly when there is a history of domestic violence in the family. The requirement of seeking parental consent in domestic violence research from either one or both parents remains quite subjective and varied both within and between jurisdictions.

Finally, Hill (2015), in her study on children's knowledge of parental alcohol problems, refers to the secrecy of such issues within families and children's choices on whether to talk about their experiences of it in a research setting. In the same way, domestic violence is a hidden issue kept secret within families, and children's involvement as a research participant runs the risk of family secrets being shared in the public space (Cater and Øverlien, 2014). Moreover, parents may use their authority as a parent or guardian to refuse consent to their child's participation as a way of avoiding family secrets being shared, in the guise of acting in the child's best interests, something which Cashmore (2006) argues is 'in effect, to censor or control the expression of children's views' (p. 970). Indeed, Campbell (2008) in his effort to recruit children to discuss their views on parental separation, found that parents' reasons for withholding consent were based on their own needs and not their child's. Obtaining parental permission for the child to speak about such personal family matters is, as Cater and Øverlien (2014) argue, an important signal to the child that they can talk about something which may have been hidden for a long time.

\section{Constructing the child victim of domestic violence}

Within the literature, the child is constructed as a victim by their direct and indirect involvement in the parental violence and abuse. Firstly, children are conceived as a victim through their actions of intervening in a violent episode and also when they become the direct target of the abuser's violence, both of which may lead to physical injury (Edleson et al., 2003). Holden refers to the child 'becoming a victim' (2003, p. 153) through their physical involvement in the incident and has been instrumental in bringing awareness to the impact on children living in violent and abusive homes. It has been vital for the child to be considered and understood as a victim rather than 
a passive observer in the scientific literature, however the construction of the child as victim has been historically based on their direct involvement be that through a 'verbal or physical' assault against them (Holden, 2003, p. 153).

Children's experiences of living in a home with patterns of control and abusive behaviours also authenticate their need for victim status. Although children are reported to intervene in the violence, it is the on-going accumulative impact of living in a home with violence and patterns of control that equally warrant their victimhood (Callaghan and Alexander, 2015; Katz, 2016). Katz (2016) argues that by looking simply through the lens of a physical incident model, we fail to acknowledge the harm incurred to children by coercive control. By adopting a protective strategy of hiding during an incident, the child victim may be out of sight, however is still tuned in to and being impacted by what is happening in the home (Callaghan and Alexander, 2015). Callaghan et al. (2017) argue that the continued 'representation of children and young people as silent and passive' in both the domestic violence literature and policy arena, fails to recognise children's 'capacity for agency' (2017, p. 3371). Similarly, Wyness refers to conceptions of the 'active child victim' (2012, p. 149), which recognises children's capacity to resist and manage their experiences of sexual abuse and argues that it is this understanding of the child that underpins supportive interventions to children. In the same way, by conceptualising the child growing up with domestic violence and abuse as an active as opposed to passive victim through the complex set of strategies they develop to keep themselves and others safe, we can begin to provide them with the emotional support they need as victims.

\section{Methodology}

The discussion to follow in this paper is based on qualitative research conducted in Ireland that sought to explore children and young people's experiences of the police response to domestic violence. Underpinned by a social constructionist and children's rights framework, the research set out to explore the subjective experiences of children and young people who come in contact with the police in the context of domestic violence. This was achieved by ascertaining the views of both the children themselves and also the adults involved in the process, who within this framework are understood to directly and indirectly shape and influence the child's experience, whilst the child is conceived as an 'agentic being' (James and Prout, 1997). Children's agency in this context is recognised by the coping strategies they employ to keep themselves and others safe in a domestically violent home. The study included data collected from a sample of ten children aged 7 and 10 years, and one young person aged 21 years, the majority of whom had experienced the police coming to their home due to a domestic violence incident involving their mother and father 
within the previous five years. Strategies to recruit a larger sample of children and particularly young people to the study failed for various reasons and will form the basis of our discussion when we consider how this group are hidden in domestic violence practice and research. Three additional subsamples included police $(n=14)$, mothers $(n=11)$ and a range of health and social care practitioners (HSCP) $(n=25)$, providing rich contextual data to triangulate the children's views (Simons, 2009). The primary method used wwas individual in-depth semi-structured interviews were. A task-based activity using vignettes was undertaken as an ethically safe method to elicit the views and perspectives of children who took part in the study (Barter and Renold, 2000). This involved inviting the child to co-construct a story which began with the police calling to a child's home after some fighting between their parents. Mothers, children and HSCP practitioners were recruited through a number of statutory and voluntary child and family services and specialist domestic violence services in both rural and urban settings in Ireland. Interviews were also conducted with police officers from the Irish police force (An Garda Síochána), working in senior ranking and specialist domestic violence units as well as frontline policing. The children and mothers were accessed through agency gatekeepers, a popular method when conducting sensitive research (Campbell, 2008; Downes et al., 2014; Callaghan and Alexander, 2015). With the expressed permission of all but one participant, interviews and focus groups were recorded electronically and transcribed verbatim. Data was coded and analysed thematically using an inductive approach (Boyatzis, 1998). Ethical approval was granted from the university Research Ethics Committee (REC) and a further three external agencies through which the recruiting of service users and practitioners took place (Campbell, 2008).

Recruiting children, but more so young people to the study, proved for a number of reasons, to be an onerous task that resulted in a small sample of children and young people who participated. The research is therefore limited by the shortfall in this population's voice, further highlighting the challenges in accessing this hard to reach group and forms the basis of the discussion within this paper. Data from the study will be used in this paper to show the multiple ways children and young people firstly were hidden in the research process through efforts to recruit this group to the study, and later how findings also shed light on the processes by which children become invisible in practice. We conclude by highlighting the interconnectedness between children's invisibility in research and practice and implications for the child victim of domestic violence.

\section{Finding a 'hard to reach' population}

Several strategies were employed to recruit children and young people (5-2lyears) to the study with the core objective being to explore their personal experiences of the police calling to their home in relation to a domestic violence incident between their 
parents. Although the focus of the study was on the child or young person's views on the police response to domestic violence, and not on their direct experiences of the abuse, this was still considered to be a study that required a particular sensitivity to ethical considerations. Time was taken in obtaining ethical approval, which was eventually secured from the university Research Ethics Committee (REC) and three additional external agencies, resulting in an ethically sound methodology that fulfilled core ethical concerns dealing with consent, confidentiality and upholding the principle to 'do no harm'. However, when it came to recruiting children and young people, similar to Campbell's (2008) experience, the study faced a number of obstacles and challenges in reaching this population.

The first, and most prominent issue, lay with the need for consent from both parents of children under 18 years to participate, which in this case meant that consent must be sought from an abusive father. This was a decision made by the university REC based on legal grounds that both parents once married or with joint guardianship had the right to be informed of, and to have their consent sought for their child's participation in research. Thus, on the advice of key informants working in the area of domestic violence, it was considered that seeking consent from abusive fathers would be too risky and it was decided to therefore only consider children of unmarried parents, or those whose father was not a legal guardian, to participate in the study - therefore bypassing the legal requirement of two parent consent. Nonetheless, this meant that gatekeepers were limited in which families they could approach about participating in the research, resulting in a small pool of children, who then for other reasons based on the gatekeeper's inside knowledge, may or may not be considered suitable to take part. Of the relatively small number of domestic violence studies that include children's voices, samples mostly include children who do not live with, or have minimal contact with their abusive parent or guardian, thereby suggesting that no threat is posed to them by the abuser if consent is not sought (Buckley, Whelan and Holt, 2006; Øverlien and Hydén, 2009; Eriksson and Nasman, 2012; Katz, 2016). Equally, anonymising data and the use of pseudonyms is an important process to ensure families who participate are not identified by the abuser (Callaghan et al., 2017). Notwithstanding these measures, the risk to children from the abuser is still an issue that must be considered and raises some dilemmas. Turning to violent fathers for consent and not turning to them could put the child in a difficult position. Not doing so might lead to the child having to keep a secret, and doing so might put the child at risk as well. There is no denying that this is a complicated subject and may be approached from different positions by ethics boards in different jurisdictions. For example, in Norway the third author was explicitly told under no circumstances to contact an abusive father for consent as this may put the child at risk. In the majority of cases of the study referred to in this paper, the children who participated, did not have on-going contact with their father and their fathers had limited rights to consent due to the non-marital status between their parents. Consequently, the experiences of children of married parents were 
marginalised in this research which resonates with Morris et al.'s (2012) argument for ethics committees to be more informed of the ethical nuances that exist around parental consent procedures when it comes to conducting research with children on domestic violence.

\section{Challenges recruiting young people to the study}

Aside from the limitations that the two parent consent requirement presented in this research, nine children (7-10 years) and regrettably only one young person participated. Interestingly, it was younger children's participation, who from the outset, was met with more scrutiny by the ethics committee and gatekeepers. However, when it came to the recruitment of adolescents and young people to the study, it was in fact this group who were more difficult to access for a number of reasons, which will now be discussed. It became apparent quite quickly from speaking with agency gatekeepers in specialist domestic violence services that they were working more with younger children. This reflected findings in the literature suggesting mothers of younger children are more commonly present in a refuge population (Hester, 2007), and also the shortfall in services for teenagers who experience domestic violence (Bracewell, 2017).

Family support services are known to offer community based support to families experiencing domestic violence and had proved to be a successful recruitment site for young people in previous studies on domestic violence (Hogan and O'Reilly, 2007). With this in mind, a number of family support teams were approached, providing them with a pack containing information booklets and consent forms designed for the different age groups of children and young people that the study was targeting. However, practitioners raised concerns about the need for father's consent and felt that this would limit the number of families that they could approach. In some cases, families that were deemed to be suitable were not approached for other reasons cited by practitioners such as pending court cases, father's involvement with the family again, difficulty making contact with the mother or other related family issues that they were dealing with, making it an inappropriate time to discuss research participation. Other gatekeepers reported difficulties in contacting adolescents to discuss the research with and those they did make contact with described being too busy with exams and social matters to take part.

Securing gatekeeper's support is not a guarantee to accessing targeted populations and has proven challenging for other children's researchers (Hogan and O'Reilly, 2007; Campbell, 2008; Powell and Smith, 2009), who in some situations have been forced to follow a less formal route to recruitment (Campbell, 2008). This in part can often also be due to a lack of services for violence-exposed children and adolescents and was the case in this research. Thus, a revised strategy was employed which involved thinking more broadly about where young people with 
experiences of domestic violence might be recruited from. As well as specialist domestic violence agencies, Callaghan et al. (2017) recruited children and young people with experiences of domestic violence, through a wider set of gatekeepers including 'school family liaison workers, counselling services or children and young people's hostels' (p. 3372). Nixon et al. (2017) report that only a small number of families will seek support through formal domestic violence services, with the remainder often presenting to agencies for reasons closely correlated to their experiences of familial violence. Based on this knowledge, recruitment sites were widened to include residential services for young people in out of home care, a youth service, teen counselling, after-care services, youth mental health service and a homeless service. Whilst some of the practitioners, working with young people in these settings, reported being aware of domestic violence occurring in the young person's family history, it was not something which had been directly named and, therefore, they did not feel comfortable raising the issue with them purely for research purposes. In the end, none of these services proved to be fruitful in accessing young people for the study, yet may well have been if there had been more time allowed to build relationships with gatekeeping figures. Also, by expanding data collection methods to include focus groups, through which those who had a direct experience of the police calling to their home in relation to domestic violence could self-identify, such agencies may have been favourable sites to uncover this hard to reach population.

Aside from these issues, young people in general can be a hard to reach group based purely on the fact that they might not prioritise research over their social life (Hill, 2006), making it difficult to arrange appointments that are often a necessary stage in building rapport with a young person before they agree to an interview. In addition, they may not wish to discuss private family matters with a stranger, considering it to be intrusive (Hill, 2006). From the limited pool of potential young people identified by gatekeepers who met the inclusion criteria, namely the requirement of two parent consent (discussed earlier in this paper), gatekeepers reported the young people declining for reasons such as; not wanting to 'drag up the past' that they wanted to move on from, fears around their safety and concerns about jeopardizing the work on rebuilding the relationship with the family. Hogan $\&$ O'Reilly (2007) reported similar reasons by adolescents for not wishing to take part in research that would involve them talking about domestic violence in their family. In another situation, two young adults over 18 years who did not require parental consent agreed to take part, but then due to unknown reasons did not follow up and became difficult to contact when it came to organising an interview, which may echo Hill's (2006) findings on young people valuing their spare time. 


\section{The practice of hiding and being hidden}

Not only were children marginalised in the research process, as evident by the small sample size despite considerable efforts made by the researcher to access this population, but the findings also pointed to children being hidden in practice. The word hidden first featured within the domestic violence literature as a way of illuminating the child's experience as victim (Abrahams, 1994), and is often used to allude to the secrecy that surrounds violence and abuse within families (Nixon et al., 2017). In the present study, data analysis across the four populations revealed the common theme of hiding. Hiding was being used by both the adults and the children as a protective strategy but in different ways and with different meaning.

\section{Children hiding as a protective strategy}

Vignettes were used as a research method to allow the children who took part in the study to express their views on the police response to domestic violence involving children. In their stories, the majority of the children described their characters as hiding in their bedroom on seeing the police arrive to the home. The children described this action as going to a 'safe place' with several of the children positioning the characters 'hiding under the bed' with a sibling and their toys, others in bed but awake or behind their bedroom door trying to listen to what was happening downstairs between the grown-ups and the police. Similarly, practitioners in the study reported children withdrawing and hiding away when violence was happening in the home. One practitioner recalled a mother telling her how her eldest child would take their younger sibling upstairs and hide as soon as the police arrived to the home, something which they had begun to do unwittingly and without the mothers' knowledge. Through their story-telling, although the children became out of sight and consciously hid when they heard the police car arriving, they also described the ways in which they employed different strategies to distract themselves. The children described their characters as 'covering their ears' or 'playing games', all of which points to their awareness of what was happening downstairs between the parents. One of the children described their characters as playing hide and seek as a way of keeping themselves happy. Again, this involves the use of hiding in a small space which can offer a sense of protection. Under the bed was described by several of the children as a 'safe place' away from the noise but also as one child suggested because 'no one will go upstairs'. Children's use of hiding as a protective strategy resonates with findings by Callaghan and Alexander (2015), who also describe children's use of small spaces to hide as a way of feeling safe during a violent episode.

In Grace's (9) story her two characters were described as hiding upstairs in their bedroom together when the police arrived. When asked if they have ever seen the police before she responds with 'em, not really since they're scared'. When asked 
if this is because they have always hidden when the police come to the house, Grace quietly nods. Lewis (2010) refers to the need to listen not only to children's words but also to the child's use of silence in the research interview as a way of communicating. Grace's silent but very clear nod suggested here that hiding from the police was something familiar to her. Although the children were all quick to say how their characters would hide from the police, all but one reported that they would be happy if the police came upstairs to check on them and offer some reassurances. This finding concurs with children's wish to be acknowledged at the scene and spoken to directly by responding officers (Radford et al, 2011; RichardsonFoster et al., 2012; Øverlien and Aas, 2016).

\section{Mothers hiding to protect}

Some of the mothers in the study talked about the ways in which they tried to hide the violence and abuse from their children as a way of protecting them. One of the mothers described hiding facial bruising with make-up from her seven-year-old and on one occasion wearing a turtle neck sweater in summer to hide bruises left on her neck from where her partner had tried to strangle her. When it came to involving the police, mothers were often reluctant to phone them and kept their abuse hidden in an effort to, as one mother described, "try to hide what happens in the home'. Faye, a young mother of one was hospitalized after a very serious assault against her by her ex- partner when her son was a few weeks old. When the hospital staff inquired about her injuries she was forced by her partner to deny she was a mother and lie to the hospital staff and later to the police when they were called. These findings are in agreement with other studies that describe how mothers often engage in protective strategies that can involve attempts to hide the abuse from their children such as bringing them to a neighbour or family member's house (Nixon et al., 2017), or in some cases not involving outside agencies to avoid drawing attention to the home (DeVoe and Smith, 2003). Jane, a mother of two, used various strategies to hide the fact that she had called the police on her children's father, including when they were younger, getting a family member to mind them in another room when the police arrived. On another occasion when the children were older, she described asking the children to use headphones and watch a movie in their bedroom after she had called the police due to an incident that occurred post-separation. Consistent with findings on parents underacknowledging children's awareness of the abuse and the impact on them (Stanley et al., 2012; Swanston, Bowyer and Vetere, 2014), Jane later questioned whether hiding the police from the children to avoid hurting them was the right thing to do as she began to realize that they see and notice a lot. 


\section{Police rendering children invisible at the incident}

All of the police participating in the research showed an awareness of the negative impact that growing up with domestic violence can have on children. Many of them recalled responding to the same families over a number of years for domestic incidents and later seeing those children as young adults become known to the police for other reasons such as involvement in crime and homelessness. Still, the issue of domestic violence by many of the respondents continued to be viewed as an adult one and this impacted on how children were responded to at the scene. As one officer described, the children's safety is a priority however, at a domestic violence incident the response is focused on the adults, and children are 'nearly a secondary'. In common with other studies (Richardson-Foster et al., 2012; Øverlien and Aas, 2016), some of the police officers in the present study spoke of there being no reason to engage with children at the scene unless they showed physical signs of injury or made a direct allegation of abuse to the responding officer. When a child presented as a clear victim through injury they then met the criteria of a victim of crime who required a formal response through a criminal justice lens which can be problematic (Elliffe and Holt, 2019). Constructions of the child as victim in this case fits with Holden's (2003) notion of the child 'becoming a victim' through their physical involvement in the incident, thereby fulfilling conceptions of a victim who is weak and who will look for help.

However, in most situations, this was not how police in this study reported children presenting at a scene of domestic violence. Officers recalled incidents were children were watching television when they arrived, playing with an iPad, at the top of the stairs or in bed asleep. There were examples of good police practice, going upstairs to check on children when parents had reported they were sleeping and showing an awareness that children might be upstairs yet awake. Police accounts of the level of engagement with children varied somewhat, from full transparency around why they were there, to more general chat about school and hobbies or a smile and wave hello, but minimal verbal interaction. A few of the officers felt that it was important to withhold the truth about why they were called to the home as a way of protecting the child. Officers spoke of telling lies to the children about why they were in the home with one giving an example of how they would say to a child 'oh your mam and your dad are helping us with something downstairs'. This officer felt strongly that it was not 'fair' for children to see what is happening and so felt that withholding the true nature of why they had been called would protect the child from the reality of the abuse. Front-line responders such as the police who rely on signs of physical harm in order to recognise the child as victim, and fail to take account of children's strategies to protect themselves and siblings by hiding, can run the risk of rendering children invisible in their response (Elliffe and Holt, 2019; Richardson-Foster et al., 2012). 


\section{Discussion}

Findings from the research highlight two key areas of concern when it comes to accessing children and young people's experiences of domestic violence, both of which centre around constructs of the child in research and practice and the ways in which they become hidden within these two arenas. Firstly, within the research context, the requirement of parental consent, in particular for adolescents over 16 years, suggests that children's agency and capacity, concepts that are treated with such high regard in the literature, are somewhat tokenistic and fail to reflect what happens in practice. James et al. (2004) argue that 'children's needs and interests may still be ignored as a consequence of adults' recourse to very particular models of the child and ideologies of childhood' (p. 190). There is no doubt that children, as much as adult participants, need protection from harm, something which a rigorous ethical process can help to ensure. However, the problem lies with a wider set of adults acting in a gatekeeping role whose model of childhood does not reflect new sociological thinking in this field (James, James and McNamee, 2004; Campbell, 2008). Within the field of domestic violence, there is a growing body of research which firmly positions the child as an active victim, who develops strategies from even a young age to cope with their experiences of living in a violent and abusive home (Callaghan et al., 2016; Katz, 2016; Øverlien, 2017). These children are already part of an adult world, however still conceived by many from a developmental perspective as too young to speak for themselves in a research capacity (Powell and Smith, 2009). Contrary to this belief, children have shown, as they did in this research, that, given a choice on whether to participate, they are indeed well capable of making that decision, including saying no to participation using their own strategies of avoidance to opt out (Hill, 2006; Callaghan et al., 2017). In the same way even younger children can avoid researchers' questions, demonstrating agency in their ability to manage their level of participation (Evang and Øverlien, 2015).

The requirement to seek two parent consent for children to participate in the present study was a contentious issue that directly resulted in the marginalisation of children of married parents, further skewing the sample. Cater and Øverlien's (2014) and Morris et al.'s (2012) discussions on the risks associated with seeking or not seeking abusive father's consent appears to be an isolated one, yet is something that requires further attention in the literature. Little is mentioned about issues surrounding father's consent - the general approach taken is to seek consent from the non-abusing parent, in most cases the mother, and assent from the child, once it is deemed safe to do so by a professional gatekeeper (Morris et al., 2012). Samples are often skewed by representing the experiences of children who do not have contact with their fathers and are positioned at the far end of the spectrum of abuse, as their mother has engaged with specialist domestic violence services. However, there are a large number of families living in the community who will never seek support through formal services for their experiences of domestic violence and it 
is these children and young people who continue to exist in the shadows. It might be helpful, therefore, for researchers to look more broadly at potential recruitment sites, and use methodologies that allow young people to self-identify as opposed to over relying on gatekeepers to recruit. Adolescents can be particularly marginalised in practice when services for younger children and mothers exist but fail to address the needs of teenagers, a group who Bracewell (2017) argues are not served well by existing domestic violence services.

Finally, when it comes to practice responses to the child victim of domestic violence, the police as first responders need to be more informed and provided with some level of training to help them to understand the long term impact that living in an abusive home can have on children, as well as the strategies which they may employ to help cope with their experiences. Constructing the child victim through a physical incident model, as Katz (2016) argues, is in this context resulting in police officers not recognising the child as a victim who requires a response. Children may choose to hide from the police at the scene, therefore, making themselves invisible unless an effort is made by officers to physically check on their whereabouts in the home and most importantly to engage directly with them and offer a response that recognizes their experiences as victim. Police viewing domestic violence as an adult issue fail to recognize the needs of the child victim separate to that of the adults. Furthermore, police should acknowledge children's agency and respond directly to them as opposed to trying to protect them through their efforts to keep the true nature of police presence in the home hidden from them.

\section{Conclusion}

This paper shows how the construction of children as hidden in practice through measures taken by mothers, practitioners and the children themselves is closely intertwined with the difficulty accessing this group in research. When their experiences of domestic violence are not acknowledged by the adults in their lives, children themselves will continue to hide to protect themselves when there is no support offered to them or recognition given to their needs as victim. Efforts to protect children by hiding the abuse from them, only make it more difficult for researchers to access this group since their position of victim remains hidden. Children, therefore, remain in the half shadows both in the domestic violence context and in the context of conducting research with a hard to reach population and this calls for a need for children's capacity, as both research participants and victims of domestic violence, to be acknowledged. 


\section{References}

Abrahams, C. (1994) Hidden Victims: Children and domestic violence. London: NCH Action for children

Alderson, P. \& Morrow, V. (2011) The Ethics of Research with Children and Young People: A practical handbook. London: SAGE

Baker, H. (2005) Involving children and young people in research on domestic violence and housing. Journal of Social Welfare and Family Law, 27, 281-297

Barter, C. \& Renold, E. (2000) 'I wanna tell you a story': Exploring the application of vignettes in qualitative research with children and young people. International Journal of Social Research Metholology, 3, 307-323

Boyatzis, R. (1998) Transforming Qualitative Information. Thousand Oaks: Sage

Bracewell, K. (2017) Teenagers' Experiences of Domestic Violence Refuges. PhD Thesis, University of Lancashire

Buckley, H., Whelan, S. \& Holt, S. (2006) Listen to Me! : Children's experience of domestic violence. Dublin: Children's Research Centre, Trinity College

Callaghan, J. \& Alexander, J. (2015) Understanding Agency and Resistance Strategies (UNARS): children's experiences of domestic violence report. Northampton: University of Northampton

Callaghan, J., Alexander, J., Sixsmith, J. \& Fellin, L. (2016) Beyond 'witnessing': Children's experiences of coercive control in domestic violence and abuse. Journal of Interpersonal Violence, 33, 10, 1551-1581

Callaghah, J., Fellin, L., Mavrou, S., Alexander, J. \& Sixsmith, J. (2017) The management of disclosure in children's accounts of domestic violence: Practices of telling and not telling. Journal of Child and Family Studies, 26, 3370-3387

Campbell, A. (2008) For their own good: Recruiting children for research. Childhood: A Global Journal of Child Research, 15, 30-49

Carroll-Lind , J., Chapman J., Gregory , J., \& Maxwell, G. (2006) The key to the gatekeepers: Passive consent and other ethical issues surrounding the rights of children to speak on issues that concern them. Child Abuse and Neglect, 30, 979-989

Cashmore, J. (2006) Ethical issues concerning consent in obtaining children's reports on their experience of violence. Child Abuse \& Neglect, 30, 969-77

Cater, A. \& Øverlien, C. (2014) Children exposed to domestic violence: a discussion about research ethics and researcher's responsibilities. Nordic Social Work Research, 4, 67-79

Coyne, I. (2010) Research with children and young people: The issue of parental (proxy) consent. Children \& Society, 24, 227-237

Devoe, E. R. \& Smith, E. L. (2003) 'Don't take my kids:' Barriers to service delivery for battered mothers and their young children. Journal of Emotional Abuse, 3, 277-294

Downes, J., Kelly, L. \& Westmarland, N. (2014) Ethics in violence and abuse research: A positive empowerment approach. Sociological Research Online, 19, 1, 1-13

Edleson, J. L. (1999) Children's witnessing of adult domestic violence. Journal of Interpersonal Violence, 14, 839-870

Edleson, J. L., Mbilinyi, L. F., Beeman, S. K. \& Hagemeister, A. K. (2003) How children are 
involved in adult domestic violence: Results from a four-city telephone survey. Journal of Interpersonal Violence, 18, 18-32

Elliffe, R. (2019) Perspectives on the Police Response to Children Present at a Domestic Violence Incident: An Irish Case Study. PhD Thesis, Trinity College Dublin

Elliffe, R. \& Holt, S. (2019) Reconceptualizing the child victim in the police response to domestic violence. Journal of Family Violence. 34, 589-600

Eriksson, M. \& Nasman, E. (2012) Interviews with children exposed to violence. Children E Society, 26, 63-73

Evang, A. \& Øverlien, C. (2015) 'If you look, you have to leave': Young children regulating research interviews about experiences of domestic violence. Journal of Early Childhood Research, 13, 113-125

Graham, A., Powell, M. A. \& Taylor, N. (2015) Ethical research involving children: Encouraging reflexive engagement in research with children and young people. Children E Society, 29, 331-343

Hester, M. (2007) Making an Impact: Children and domestic violence: A reader. London: Jessica Kingsley

Hill, L. (2015) 'Don't make us talk!': Listening to and learning from children and young people living with parental alcohol problems. Children \& Society, 29, 344-354

Hill, M. (2006) Children's voices on ways of having a voice: Children's and young people's perspectives on methods used in research and consultation. Childhood, 13, 69-89

Hill, M. \& Tisdall, K. (1997) Children and Society. Harlow: Addison Wesley/Longman

Hogan, F. \& O'Reilly, M. (2007) Listening to Children: Children's stories of domestic violence. Dublin: The Stationery Office

Holden, G. W. (2003) Children exposed to domestic violence and child abuse: Terminology and taxonomy. Clinical Child and Family Psychology Review, 6, 151-160

Holt, S. (2011) Domestic abuse and child contact: Positioning children in the decision-making process. Child Care in Practice, 17, 327-346

Holt, S. (2015) Post-separation fathering and domestic abuse: Challenges and contradictions. Child Abuse Review, 24, 210-222

Houghton, C. (2018) Voice, agency, power: A framework for young survivors' participation in national domestic abuse policy-making. in S. Holt, C. Øverlien and J. Devaney, (Eds.) Responding to Domestic Violence: Emerging challenges for policy, practice and research in Europe. London Jessica: Kingsley

Iltis, A. S. (2013) Parents, adolescents, and consent for research participation. Journal of Medicine and Philosophy, 38, 332-346

James, A. (2007) Giving voice to children's voices: Practices and problems, pitfalls and potentials. American Anthropologist, 109, 261-272

James, A., James, A. \& McNamee, S. (2004) Turn down the volume. Not hearing children in family proceedings. Child \& Family Law Quarterly, 16, 189-202

James, A. \& Prout, A. (1997) Constructing and Reconstructing Childhood: Contemporary issues in the sociological study of childhood. London: Falmer 
Katz, E. (2015) Recovery-promoters: Ways in which children and mothers support one another's recoveries from domestic violence. British Journal of Social Work, 45, il53-il69

Katz, E. (2016) Beyond the physical incident model: How children living with domestic violence are harmed by and resist regimes of coercive control. Child Abuse Review, 25, 46-59

Lewis, A. (2010) Silence in the context of 'child voice'. Children \& Society, 24, 14-23

Liu, C., Cox, R. B., Washburn, I. J., Croff, J. M. \& Crethar, H. C. (2017) The effects of requiring parental consent for research on adolescents' risk behaviors: A meta-analysis. Journal of Adolescent Health, 61, 45-52

McClinton Appollis, T., Lund, C., de Vries, P. J., \& Mathews, C. (2015) Adolescents' and adults' experiences of being surveyed about violence and abuse: A systematic review of harms, benefits, and regrets. American Journal of Public Health, 105, 2, e31-e45

McIntosh, J. (2003) Children living with domestic violence: Research foundations for early intervention. Journal of Family Studies, 9, 219-234

Morris, A., Kelsey, H. \& Humphreys, C. (2012) Ethical and safe: Research with children about domestic violence. Research Ethics, 8, 125-139

Nixon, K. L., Tutty, L. M., Radtke, H., Ateah, C. A. \& Ursel, E. J. (2017) Protective strategies of mothers abused by intimate partners: Rethinking the deficit model. Violence Against Women, 23, 1271-1292

Øverlien, C. (2017) 'Do you want to do some arm wrestling?': Children's strategies when experiencing domestic violence and the meaning of age. Child \& Family Social Work, 22, 680-688

$\emptyset$ verlien, C. \& Aas, G. (2016) The police patrols and children experiencing domestic violence. Police Practice and Research, 17, 434-447

$\emptyset$ verlien, C. \& Holt, S. (2018) Including children and adolescents in domestic violence research. in S. Holt, C. Øverlien and J. Devaney, (Eds.) Responding to Domestic Violence: Emerging challenges for policy, practice and research in Europe. London: Jessica Kingsley

$\varnothing$ verlien, C. \& Hyden, M. (2009) Children's actions when experiencing domestic violence. Childhood, 16, 479-496

Pernebo, K. \& Almqvist, K. (2016) Young children's experiences of participating in group treatment for children exposed to intimate partner violence: A qualitative study. Clinical Child Psychology and Psychiatry, 21, 119-32

Powell, M. A. \& Smith, A. B. (2009) Children's participation rights in research. Childhood, $16,124-142$

Radford, L., Aitken, R., Miller, P., Ellis, J., Roberts, J. \& Firkic, A. (2011) Meeting the Needs of Children Living with Domestic Violence In London. London: NSPCC

Richardson-Foster, H., Stanley, N., Miller, P. \& Thomson, G. (2012) Police intervention in domestic violence incidents where children are present: Police and children's perspectives. Policing and Society, 22, 220-234

Simons, H. (2009) Case Study Research in Practice. London, Sage

Stanley, N., Miller, P. \& Foster, H. R. (2012) Engaging with children's and parents' perspectives on domestic violence. Child \& Family Social Work, 17, 192-201 
Swanston, J., Bowyer, L. \& Vetere, A. (2014) Towards a richer understanding of school-age children's experiences of domestic violence: The voices of children and their mothers. Clinical Child Psychology and Psychiatry, 19, 184-201

Tisdall, E. K. M. \& Punch, S. (2012) 'Not so 'new'? Looking critically at childhood studies. Children's Geographies, 10, 249-264

United Nations (1989) Convention on the Rights of the Child. Geneva: United Nations

Wyness, M. G. (2006) Childhood and Society: An introduction to the sociology of childhood. Basingstoke: Palgrave Macmillan 